\title{
Non-pharmacological interventions in dementia
}

\author{
Simon Douglas, Ian James \& Clive Ballard
}

\begin{abstract}
It is increasingly recognised that pharmacological treatments for dementia should be used as a secondline approach and that non-pharmacological options should, in best practice, be pursued first. This review examines current non-pharmacological approaches. It highlights the more traditional treatments such as behavioural therapy, reality orientation and validation therapy, and also examines the potential of interesting new alternative options such as cognitive therapy, aromatherapy and multisensory therapies. The current literature is explored with particular reference to recent research, especially randomised controlled trials in the area. Although many non-pharmacological treatments have reported benefits in multiple research studies, there is a need for further reliable and valid data before the efficacy of these approaches is more widely recognised.
\end{abstract}

Traditionally, cognitive problems have been the main focus of interest in treatment and research for people with dementia. It is becoming increasingly recognised, however, that a number of common noncognitive symptoms also provide problems not only for the person with dementia and the carers, but also in relation to clinical management. The most obvious are agitation, aggression, mood disorders and psychosis, but other important symptoms include sexual disinhibition, eating problems and abnormal vocalisations. These have been grouped together under the umbrella term 'behavioural and psychological symptoms of dementia' (BPSD) by the International Psychogeriatric Association (Finkel et al, 1996). These symptoms are a common reason for institutionalisation of people with dementia and they increase the burden and stress of caregivers (Schultz \& Williamson, 1991). Good clinical practice requires the clinician first to exclude the possibility that behavioural or psychological symptoms are the consequence of concurrent physical illness (e.g. infections, constipation), and second to try nonpharmacological approaches before considering pharmacological interventions.

All too often in practice, however, pharmacological approaches involving neuroleptic or other sedative medication are used as the first-line treatment, despite the modest evidence of efficacy from clinical trials where high placebo response rates are frequently seen (Ballard \& O'Brien, 1999). Inappropriate and unnecessary prescribing has become such a problem that more than $40 \%$ of people with dementia in care facilities in the developed world are taking neuroleptic drugs (Margallo-Lana et al, 2001). The prescription of these medications without attempting other treatment options is of particular concern because of the substantial adverse effects associated with their use, especially in people with dementia. Side-effects such as sedation, falls and extrapyramidal signs are well-known, and more recent work indicates that neuroleptic treatment of dementia leads to reduced well-being and quality of life (Ballard et al, 2001) and may even accelerate cognitive decline (McShane et al, 1997).

In this article we discuss the types of behavioural and psychological symptoms that are appropriate for intervention, and then examine the current use of non-pharmacological interventions. The article is intended to apply to all common late-onset dementias and to no subtype in particular.

We carried out an extensive review of the literature on non-pharmacological treatments for dementia using Medline and other related searches, but this is not intended to be a formal systematic review.

\footnotetext{
Simon Douglas is a clinical research nurse at the Wolfson Research Centre in Newcastle upon Tyne. He is currently coordinating a number of studies, particularly on dementia in nursing and residential homes and providing input into a new trial of nonpharmacological interventions for dementia. Ian James is a consultant clinical psychologist at the Centre for the Health of the Elderly at Newcastle General Hospital and a research tutor at the Univeristy of Newcastle upon Tyne. His current interests are in using interventions such as cognitive-behavioural and interpersonal therapy with elderly patients and their care staff to deal with challenging behaviour. Clive Ballard (Wolfson Research Centre, Newcastle General Hospital, Westgate Road, Newcastle NE4 6BE, UK. E-mail: c.g.ballard@ncl.ac.uk) has recently taken up post as Professor of Age Related Disorders at Kings' College London/Institute of Psychiatry, having previously been Professor of Old Age Psychiatry at the Univeristy of Newcastle upon Tyne. Ongoing research programmes include forms of dementia, psychatric symptoms of dementia and the use of sedative drugs in dementia.
} 


\section{The nature of the behaviours}

When reviewing this area, it is important to note that there is an ongoing debate regarding the definitions and basic terminology for 'non-cognitive' symptoms. The term currently favoured in the psychiatric literature is 'behavioural and psychological symptoms of dementia', but most of the psychology community still use the label 'challenging behaviour' (Emerson et al, 1995). Within these broader terms, further distinctions have been made (e.g. Cohen-Mansfield et al, 1992; Allen-Burge et al, 1999). Allen-Burge et al distinguish between behavioural excesses (such as disruptive vocalisation or aggression) and behavioural deficits (such as lack of social interaction or lack of self-care).

In Allen-Burge et al's terminology, until recently the main focus of treatment has been excessive behaviours, because of the disruption they cause both for the person with dementia and the carers.

It is relevant to note that, in many currently used approaches, the disruptive behaviours are often not addressed directly, but are taken as an indication of underlying distress or unmet need. For example, Cohen-Mansfield (2000) has recently produced an 'unmet needs model for agitation'. Her model distinguishes three main functions of behaviours in relation to needs: behaviours to obtain or meet a need (e.g. pacing to provide stimulation); behaviours to communicate a need (e.g. repetitive questioning); and behaviours that result from an unmet need (e.g. aggression triggered by pain or discomfort). This model is particularly helpful in terms of therapy because the focus on the patient's needs helps to target interventions more appropriately (e.g. the use of pain relief, facilitation of communication).

\section{Non-pharmacological interventions}

An increasing number of non-pharmacological therapies are now available for people with dementia (Box 1). It should be noted that there are several areas of overlap between these therapies and, in fact, each approach is rarely used in isolation (Ballard et al, 2001). It is therefore important for a clinician to have some knowledge of a number of these approaches, enabling a combination of treatments tailored to the individual requirements of the patient.

\section{Standard non-pharmacological therapies Behavioural therapy}

Traditionally, behavioural therapy has been based on principles of conditioning and learning theory using strategies aimed at suppressing or eliminating challenging behaviours. More recently, positive programming methodologies (La Vigna \& Donnellan, 1986) have used non-aversive methods in helping to develop more functional behaviours. Moniz-Cook (1998) suggests that behavioural analysis is often the starting point of most other forms of therapeutic intervention in this area. Furthermore, she suggests that modern behavioural approaches can be wholly consistent with person-centred care. Behavioural therapy requires a period of detailed assessment in which the triggers, behaviours and reinforcers (also known as the ABC: antecedents, behaviours and consequences) are identified and their relationships made clear to the patient. The therapist will often use some kind of chart or diary to gather information about the manifestations of a behaviour and the sequence of actions leading up to it. Interventions are then based on an analysis of these findings. Emerson (1998) suggests focusing on three key features when designing an intervention: taking account of the individual's preferences; changing the context in which the behaviour takes place; and using reinforcement strategies and schedules that reduce the behaviour.

The efficacy of behavioural therapy has been demonstrated in the context of dementia in only a small number of studies (Burgio \& Fisher, 2000). For example, there is evidence of successful reductions in wandering, incontinence and other forms of stereotypical behaviours (Woods, 1999). Meares \& Draper (1999) presented case studies testifying to the efficacy of behavioural therapy, but they noted that the behaviours had diverse causes and maintaining factors, and advised that behavioural interventions must be tailored to individual cases.

\author{
Box 1 Non-pharmacological therapies \\ Standard therapies \\ Behavioural therapy \\ Reality orientation \\ Validation therapy \\ Reminiscence therapy \\ Alternative therapies \\ Art therapy \\ Music therapy \\ Activity therapy \\ Complementary therapy \\ Aromatherapy \\ Bright-light therapy \\ Multisensory approaches \\ Brief psychotherapies \\ Cognitive-behavioural therapy \\ Interpersonal therapy
}




\section{Reality orientation}

Reality orientation is one of the most widely used management strategies for dealing with people with dementia (for a review, see Holden \& Woods, 1995). It aims to help people with memory loss and disorientation by reminding them of facts about themselves and their environment. It can be used both with individuals and with groups. In either case, people with memory loss are oriented to their environment using a range of materials and activities. This involves consistent use of orientation devices such as signposts, notices and other memory aids. There is debate regarding the efficacy of the approach, although Bleathman \& Morton (1988) found that reality orientation sessions could increase people's verbal orientation in comparison with untreated control groups. However, it has also been claimed that reality orientation can remind the participants of their deterioration (Goudie \& Stokes, 1989), and Baines et al (1987) found an initial lowering of mood in those attending the sessions. It has also been suggested that carers may experience further frustration at using the method and at having repeatedly to try to orient individuals, with little noticeable long-term effect (Hitch, 1994). Despite these concerns, the debate concerning efficacy has been largely settled following Spector et al's (2002a) favourable review of the six randomised controlled trials of this therapy. Indeed, on the basis of the positive findings, the authors proposed that it was time for a rehabilitation of reality orientation. They had previously developed a pilot programme to this effect (Spector et al, 2001).

\section{Validation therapy}

Validation therapy was developed as an antidote to the perceived lack of efficacy of reality orientation. It was suggested by its originator, Naomi Feil, that some of the features associated with dementia such as repetition and retreating into the past were in fact active strategies on the part of the affected individual to avoid stress, boredom and loneliness. She argues that people with dementia can retreat into an inner reality based on feelings rather than intellect, as they find the present reality too painful. Validation therapy therapists therefore attempt to communicate with individuals with dementia by empathising with the feelings and meanings hidden behind their confused speech and behaviour. It is the emotional content of what is being said that is more important than the person's orientation to the present. There have been relatively few empirical studies assessing the efficacy of the validation approach, as noted by Feil (1967), Mitchell (1987) and Hitch (1994). Hitch noted that validation therapy promotes contentment, results in less negative affect and behavioural disturbance, produces positive effects and provides the individual with insight into external reality. It was, however, suggested that therapists could become too focused on confused communication and could fail to identify simple explanations such as pain or hunger. Neal \& Briggs (2002) evaluated validation therapy across a number of controlled trials, employing cognitive and behavioural measures. They concluded that despite some positive indicators, the jury was still out with respect to its efficacy.

\section{Reminiscence therapy}

Reminiscence therapy involves helping a person with dementia to relive past experiences, especially those that might be positive and personally significant, for example family holidays and weddings. This therapy can be used with groups or with individuals. Group sessions tend to use activities such as art, music and artefacts to provide stimulation. Reminiscence therapy is seen as a way of increasing levels of well-being and providing pleasure and cognitive stimulation. Few highquality studies have been conducted in this area, and Spector et al (2002b) identified only two randomised controlled trials. From their limited data-set they concluded that there was little evidence of a significant impact of the approach. O'Donovan (1993), however, stated that, although there is little indication of cognitive improvement, there is some evidence suggesting improvements in behaviour, well-being, social interaction, self-care and motivation (Gibson, 1994). It is also claimed that premorbid aspects of the person's personality may re-emerge during reminiscence work (Woods, 1999). The therapy also has a great deal of flexibility as it can be adapted to the individual. A person with severe dementia can still gain pleasure from listening to an old record, for instance.

\section{Alternative non-pharmacological therapies}

As in other areas of health care, alternative therapies are gaining currency in the treatment of people with dementia. These therapies often still lack empirical evidence relating to their effectiveness (Marshall \& Hutchinson, 2001), but this issue is gradually being addressed. A review of some of the most popular forms of alternative therapy is provided below.

\section{Art therapy}

Art therapy has been recommended as a treatment for people with dementia as it has the potential to provide meaningful stimulation, improve social interaction and improve levels of self-esteem (Killick 
\& Allan 1999). Activities such as drawing and painting are thought to provide individuals with the opportunity for self-expression and the chance to exercise some choice in terms of the colours and themes of their creations.

\section{Music therapy}

Several studies have reported benefits gained by people with dementia from music therapy (Killick \& Allan, 1999). The therapy may involve engagement in a musical activity (e.g. singing or playing an instrument), or merely listening to songs or music. Lord \& Garner (1993) showed increases in levels of well-being, better social interaction and improvements in autobiographical memory in a group of nursing home residents who regularly had music played to them. Such improvements were not observed in a comparison group engaged in other activities. Cohen-Mansfield \& Werner (1997) compared three types of intervention for people with abnormal vocalisations, and found that music therapy significantly reduced the behaviour. More recently, a study by Gerdner (2000) found a significant reduction in agitation in people with dementia who were played an individualised programme of music as opposed to traditional relaxation music.

\section{Activity therapy}

Activity therapy involves a rather amorphous group of recreations such as dance, sport and drama. It has been shown that physical exercise can have a number of health benefits for people with dementia, for example reducing the number of falls and improving mental health and sleep (King et al, 1997) and improving their mood and confidence (Young \& Dinan, 1994). In addition, Alessi et al (1999) found in a small-scale controlled study that daytime exercise helped to reduce daytime agitation and night-time restlessness. An interesting approach to dance therapy is described by Perrin (1998), who employed a form of dance known as 'jabadeo', which involves no prescriptive steps or motions but allows the participants to engage with each other in interactive movements. It is relevant to note that this may also fulfil a need for non-sexual physical contact which many people with dementia find soothing.

\section{Complementary therapy}

The Mental Health Foundation recently conducted a study into the use of complementary therapies in the field of mental health that included their use in dementia. From this work, it was evident that a number of different therapies were being employed, for example massage, reflexology, reiki, therapeutic healing, herbal medicine and aromatherapy. The results of this survey have been reviewed by Wiles \& Brooker (2003). In terms of effectiveness, it was evident that careful consideration was needed to identify what was meant by 'effective' (e.g. were the therapies aiming to improve cognitive abilities or levels of well-being?).

In general, most of the complementary therapies have not received a great deal of empirical investigation. An exception to this is aromatherapy, which is described in more detail below.

\section{Aromatherapy}

Aromatherapy is one of the fastest growing of all the complementary therapies (Burns et al, 2002). It appears to have several advantages over the pharmacological treatments widely used for dementia. It has a positive image and its use aids interaction while providing a sensory experience. It also seems to be well tolerated in comparison with neuroleptic or sedative medication. The two main essential oils used in aromatherapy for dementia are extracted from lavender and melissa balm. They also have the advantage that there are several routes of administration such as inhalation, bathing, massage and topical application in a cream. This means that the therapy can be targeted at individuals with different behaviours: inhalation may be more effective than massage for a person with restlessness, for instance. There have been some positive results from recent controlled trials which have shown significant reductions in agitation, with excellent compliance and tolerability (e.g. see Ballard et al, 2002). [An article on the use of aromatherapy in dementia (Holmes \& Ballard, 2004) will appear in the next issue of APT. Ed.]

\section{Other therapies}

Two therapies worthy of mention in this section are bright-light therapy and multisensory approaches. Both of these have received some research attention and have demonstrated positive outcomes. For example, bright-light therapy has been increasingly used in an attempt to improve fluctuations in diurnal rhythms that may account for night-time disturances and 'sundown syndrome' (recurring confusion or agitation in the late afternoon or early evening) in people with dementia. Three recent controlled trials have been published with some evidence for improving restlessness and with particular benefit for sleep disturbances (e.g. see Haffmanns et al, 2001).

Multisensory approaches usually involve using a room designed to provide several types of sensory stimulation such as light (often in the form of fibre optics which can move and be flexible), texture 
(cushions and vibrating pads), smell and sound. The use of these resources is tailored to the individual and therefore not all of the available forms of stimulation may be used in one session. A description and discussion of multisensory therapy in psychiatric care has appeared in an earlier issue of APT (Baillon et al, 2002).

The use of such rooms with people with dementia has centred mainly on those with more severe symptoms. A study by van Diepen et al (2002) showed some positive effects on agitation, but the results failed to reach significance. Burns et al (2000) have reviewed the increasing use of multisensory rooms. They concluded that the area was worthy of future research, but that the available evidence lacked scientific rigour.

\section{Brief psychotherapies \\ Cognitive-behavioural therapy}

Over the past 10 years there has been an increasing interest in applying some of the brief therapeutic frameworks such as cognitive-behavioural therapy (CBT) and interpersonal therapy to dementia. For example, Teri \& Gallagher-Thompson (1991) reported positive findings from a clinical trial of CBT with people in the early stages of Alzheimer's disease. Individual and group CBT has also been used by other researchers with some favourable results (Kipling et al, 1999).

\section{Interpersonal therapy}

Interpersonal therapy, as the name suggests, examines the individual's distress within an interpersonal context (Weissman et al, 2000). In this sense, there is a great deal of overlap with the person-centred work of Kitwood (1997) and Stokes (2000). It uses a specific framework in which the individual's distress is conceptualised through one of four domains: interpersonal disputes; interpersonal/personality difficulties; bereavement; and transitions/life events. Despite there being good empirical evidence of the success of this form of treatment with older people (Miller \& Reynolds, 2002), it has only recently been used with dementia (James et al, 2003).

\section{Limitations}

Both CBT and interpersonal therapy have limitations, particularly with severe dementia. Nevertheless, owing to the fact that these therapies have relatively simple conceptual models underpinning them, they have been shown to be helpful, even for severe cognitive impairment (James et al, 1999; James, 2001). For example, James believes that a CBT perspective is very suitable for people with dementia, as many of the behavioural difficulties encountered emerge through one or more of the following cognitive features: cognitive misinterpretations, biases, distortions, erroneous problem-solving strategies and communication difficulties. In other words, many of the challenges posed by people with dementia are due to their thinking style - the very thing that is addressed in CBT. Hence, CBT offers a framework within which to understand the individual's distressing experiences, and this understanding allows the clinician to target interventions more appropriately. In this sense, it is argued that CBT is a person-centred therapy.

\section{Conclusions}

Having reviewed many of the treatments currently available, it is worth noting their common features. One striking thing is the move towards more personcentred forms of care (Kitwood, 1997). Within this approach, greater attempts are made to understand the individual's experience of dementia and to employ strategies to improve the person's quality of life. A further shared feature is the systemic perspective, that is, the need to work with systems (families, professional carers, organisations, etc.). Indeed, care staff and families are usually integral to treatment strategies. They are essential in obtaining valid and reliable information and constructing appropriate formulations. Also, they are key to conducting any interventions reliably. It is evident, therefore, that training of carers (both professional and family) is an important part of most treatment programmes. In fact, one study study (Bird et al, 2002) suggested that the most common interventions for psychological and behavioural symptoms of dementia were not necessarily specific therapies but working with carers or nursing home staff to change the attitudes and behaviour of those in their care. Despite the relevance of this issue, there remain relatively few high-quality studies in the area (e.g. Marriott et al, 2000). Clearly, training and support are important and worthy of further study; future studies need to be large and also include follow-up methodologies.

The field of dementia care is expanding, with an increasing number of articles on psychosocial interventions; to that extent the future looks promising. However, it is noted that there is a fundamental weakness within the current literature that clearly requires addressing. This concerns the limited attention paid to process issues (i.e. details outlining the mechanism of change underpinning the interventions). The available studies have been good at presenting the contents of intervention 
programmes, but usually fail to outline how the interventions were conducted (communication strategies, interpersonal style, feedback mechanisms, staff training issues). Indeed, if these issues were better delineated, it would help therapists develop, refine and improve the manner in which they implement their treatment programmes (James et al, 2003).

\section{References}

Allen-Burge, R., Stevens, A. \& Burgio, L. (1999) Effective behavioural interventions for decreasing dementia-related challenging behaviour in nursing homes. International Journal of Geriatric Psychiatry, 14, 213-228.

Alessi, C., Yoon, E., Schnelle, J., et al (1999) A randomised trial of a combined physical activity and environment intervention in nursing home residents: do sleep and agitation improve? Journal of the American Geriatrics Society, 47, 784-791.

Baillon, S., van Diepen, E. \& Prettyman, R. (2002) Multisensory therapy in psychiatric care. Advances in Psychiatric Treatment, 8, 444-450.

Baines, S., Saxby, P. \& Ehlert, K. (1987) Reality orientation and reminiscence therapy: a controlled cross-over study of elderly confused people. British Journal of Psychiatry, 151, 222-231.

Ballard, C. G. \& O'Brien, J. T. (1999) Pharmacological treatment of behavioural and psychological signs in Alzheimer's disease: how good is the evidence for current pharmacological treatments? BMJ, 319, 138-139.

Ballard, C. G., O'Brien, J., James, I., et al (2001) Dementia: Management of Behavioural and Psychological Symptoms. Oxford: Oxford University Press.

Ballard, C. G., O'Brien, J., Reichelt, K., et al (2002) Aromatherapy as a safe and effective treatment for the management of agitation in severe dementia: the results of a double blind, placebo controlled trial. Journal of Clinical Psychiatry, 63, 553-558.

Bird, M., Llewellyn-Jones, R., Smithers, H., et al (2002) Psychosocial Approaches to Challenging Behaviour in Dementia: A Controlled Trial. Report to the Commonwealth Department of Health and Ageing. Canberra: CDHA.

Bleathman, C. \& Morton, I. (1988) Validation therapy and the demented elderly. Journal of Advanced Nursing, 13, 511-514.

Burgio, L. \& Fisher, S. (2000) Application of psychosocial interventions for treating behavioural and psychological symptoms of dementia. International Psychogeriatrics, 12, (suppl. 1), 351-358.

Burns, I., Cox, H. \& Plant, H. (2000) Leisure or therapeutics? Snoezelen and the care of older persons with dementia. International Journal of Nursing Practice, 6, 118-126.

Burns, A., Byrne, J., Ballard, C., et al (2002) Sensory stimulation in dementia. An effective option for managing behavioural problems. BMJ, 325, 1312-1313.

Cohen-Mansfield, J. (2000) Use of patient characteristics to determine non-pharmacologic interventions for behavioural and psychological symptoms of dementia. International Psychogeriatrics, 12 (suppl. 1), 373-380.

Cohen-Mansfield, J. \& Werner, P. (1997) Management of verbally disruptive behaviors in nursing home residents. Journals of Gerontology Series A - Biological Sciences and Medical Sciences, 52, 369-377.

Cohen-Mansfield, J., Marx, M. \& Werner, P. (1992) Agitation in elderly persons: an integrative report of findings in a nursing home. International Psychogeriatrics, 4 (suppl. 4), 221-240.

Emerson, E. (1998) Working with people with challenging behaviour. In Clinical Psychology and People with Intellectual Disabilities (eds E. Emerson, C. Hatton, J. Bromley, et al) pp. 127-153. Chichester: John Wiley \& Sons.

Emerson, E., Thompson, S., Reeves, D., et al (1995) Descriptive analysis of multiple response topographies of challenging behaviour across two settings. Research in Developmental Disabilities, 16, 301-329.
Feil, N. (1967) Group therapy in a home for the aged. Gerontologist, 7(1), 192-195.

Finkel, S. I., Costa de Silva, J., Cohen, G., et al (1996) Behavioural and psychological signs and symptoms of dementia: a consensus statement on current knowledge and implications for research and treatment. International Journal of Psychogeriatrics, 8, 497-500.

Gerdner, L. (2000) Effects of individualized versus classical "relaxation" music on the frequency of agitation in elderly persons with Alzheimer's disease and related disorders. International Psychogeriatrics, 12, 49-65.

Gibson, F. (1994) What can reminiscence contribute to people with dementia? In Reminiscence Reviewed: Evaluations, Achievements, Perspectives (ed. J. Bornat), pp. 46-60. Buckingham: Open University Press.

Goudie, F. \& Stokes, G. (1989) Understanding confusion. Nursing Times, 85, 35-37.

Haffmanns, P. M., Sival, R. C., Lucius, S. A., et al (2001) Bright light therapy and melatonin in motor restless behaviour in dementia: a placebo-controlled study. International Journal of Geriatric Psychiatry, 16, 106-110.

Hitch, S. (1994) Cognitive therapy as a tool for the caring elderly confused person. Journal of Clinical Nursing, 3, 4955.

Holden, U. P. \& Woods, R. T. (1995) Positive Approaches to Dementia Care (3rd edn). Edinburgh: Churchill Livingstone.

Holmes, C. \& Ballard, C. (2004) Aromatherapy in dementia. Advances in Psychiatric Treatment, 10, in press.

James, I. (2001) Psychological therapies and approaches in dementia. In Dementia: Management of Behavioural and Psychological Symptoms (eds C. G. Ballard, J. O’Brien, I. James, et al). Oxford: Oxford University Press.

James, I., Kendell, K. \& Reichelt, F. K. (1999) Using a cognitive rationale to conceptualise anxiety in people with dementia. Behavioural and Cognitive Psychotherapy, 27, 345-351.

James, I., Powell, I. \& Kendell, K. (2003) A cognitive perspective on training in care homes. Journal of Dementia Care, 11, 2224.

Killick, J. \& Allan, K. (1999) The arts in dementia care: tapping a rich resource. Journal of Dementia Care, 7, 35-38.

King, A., Oman, R., Brassington, G., et al (1997) Moderate intensity exercise and self-rated quality of sleep in older adults. A randomised controlled trial. JAMA, 277, 32-37.

Kipling, T., Bailey, M. \& Charlesworth, G. (1999) The feasibility of a cognitive behavioural therapy group for men with a mild/moderate cognitive impairment. Behavioural and Cognitive Psychotherapy, 27, 189-193.

Kitwood, T. (1997) Dementia Reconsidered: The Person Comes First. Buckingham: Open University Press.

La Vigna, G. \& Donnellan, A. (1986) Alternative to Punishment: Solving Behaviour Problems with Non-aversive Strategies. New York: Irvington.

Lord, T. \& Garner, E. (1993) Effects of music on Alzheimer patients. Perceptual and Motor Skills, 76, 451-455.

Margallo-Lana, M., Swann, A., O'Brien, J., et al (2001) Prevalence and pharmacological management of behavioural and psychological symptoms amongst dementia sufferers living in care environments. International Journal of Geriatric Psychiatry, 16, 39-44.

Marriott, A., Donaldson, C., Tarrier, N., et al (2000) Effectiveness of cognitive-behavioural family intervention in reducing the burden of care in carers of patients with Alzheimer's disease. British Journal of Psychiatry, 176, 557562.

Marshall, M. \& Hutchinson, S. (2001) Journal of Advanced Nursing, 35, 488-496.

McShane, R., Keene, J., Gedling, K., et al (1997). Do neuroleptic drugs hasten cognitive decline in dementia? Prospective study with necropsy follow-up. BMJ, 314, 211-212.

Meares, S. \& Draper, B. (1999) Treatment of vocally disruptive behaviour of multifactorial aetiology. International Journal of Geriatric Psychiatry, 14, 285-290.

Miller, M. \& Reynolds, C. (2002) Interpersonal psychotherapy. In Psychological Therapies with Older People: Developing Treatments for Effective Practice (eds J. Hepple, P. Pearce, \& G. Wilkinson), pp. 103-127. Hove: Brunner-Routledge. 
Mitchell, G. J. (1987) An Analysis of the Communication Process and Content with Confused Elderly Clients during Validation Therapy. MA Thesis. Toronto: University of Toronto, School of Nursing.

Moniz-Cook, E., Agar, S., Silver, M., et al (1998) Can staff training reduce behavioural problems in residential care for the elderly mentally ill? International Journal of Geriatric Psychiatry, 13, 149-158.

Neal, M. \& Briggs, M. (2002) Validation therapy for dementia. Cochrane Library, issue 3. Oxford: Update Software.

O'Donovan, S. (1993) The memory lingers on. Elderly Care, 5, 27-31.

Perrin, T. (1998) Lifted into a world of rhythm and melody. Journal of Dementia Care, 6, 22-24.

Schultz, R. \& Williamson, G. H. (1991) A 2-year longitudinal study of depression among Alzheimer's caregivers. Psychology and Aging, 6, 569-578.

Spector, A., Orrell, M., Davies, S., et al (2001) Can reality orientation be rehabilitated? Development and piloting of an evidence-based programme of cognition-based therapies for people with dementia. Neuropsychological Rehabilitation, 11, 377-397.

Spector, A., Orrell, M., Davies, S., et al (2002a) Reality orientation for dementia. Cochrane Library, issue 3. Oxford: Update Software.

Spector, A., Orrell, M., Davies, S., et al (2002b) Reminiscence therapy for dementia. Cochrane Library, issue 3. Oxford: Update Software.

Stokes, G. (2000) Challenging Behaviour in Dementia. Bicester: Speechmark.

Teri, L. \& Gallagher-Thompson, D. (1991) Cognitivebehavioural interventions for treatment of depression in Alzheimer's patients. Gerontologist, 31, 413-416.

Van Diepen, E., Baillon, S., Redman, J., et al (2002) A pilot study of the physiological and behavioural effects of Snoezelen in dementia. British Journal of Occupational Therapy, 65(2), 61-66

Weissman, M., Markowitz, J. \& Klerman, G. (2000) Comprehensive Guide to Interpersonal Therapy. New York: Basic Books.

Wiles, A. \& Brooker, D. (2003) Complementary therapies in dementia care. Journal of Dementia Care, 11, 31-36.

Woods, R. T. (1999) Psychological Problems of Ageing. Chichester: John Wiley and Sons.

Young, A. \& Dinan, S. (1994) ABC of sports medicine. Fitness for older people. $B M J, 309,331-334$.

\section{Multiple choice questions}

\section{Non-pharmacological treatments for dementia:}

a can be effective

b should always be used as a second line of treatment to medication

c aim to improve people's cognitive abilities

$\mathrm{d}$ require the cooperation of staff

e are becoming increasingly well researched.
2 Pharmacological treatments of dementia:

a can have many unwanted side-effects

b are usually well prescribed and monitored

c are used excessively in many care facilities

d should not be used in treatment of BPSD

e currently include the common use of neuroleptics to treat non-cognitive symptoms.

3 When discussing non-cognitive symptoms of dementia:

a memory problems and language disorders are common non-cognitive symptoms of dementia

$\mathrm{b}$ the terms behavioural and psychological symptoms of dementia and challenging behaviours are synonymous

c one is solely talking about disruptive and agitated behaviours

d neither psychological nor pharmacological treatments seem to be effective

e a non-pharmacological perspective would tend to view a problematic behaviour as a manifestation of an underlying 'unmet' need.

\section{A person with dementia:}

a can be offered a number of different forms of nonpharmacological intervention

b can only be helped in the early stages of the dementia

c requires a moderate degree of intellectual insight in order to benefit from the non-pharmacological treatments

d can be helped by unmet needs analysis, in which the therapist identifies the patient's potential needs

e is unable to engage in the standard forms of psychotherapy (e.g. CBT, interpersonal therapy).

5 When employing non-pharmacological treatments:

a carers and/or staff should be willing to work/help with the treatment regimen

b they should be used as an adjunct to pharmacological treatments

c carers and/or staff may require both training and support in order to undertake the treatments effectively

d improvements may occur across a range of abilities (e.g. orientation, sleep, quality of life)

e one should always try to orient individuals with dementia to what is happening in the present, so that they can engage in meaningful conversations and interactions with others.

\section{MCQ answers}

\begin{tabular}{|c|c|c|c|c|}
\hline & 2 & 3 & 4 & \\
\hline $\mathrm{T}$ & a $\mathrm{T}$ & a & a $\mathrm{T}$ & \\
\hline F & b F & b I & b F & \\
\hline $\mathrm{F}$ & c $\mathrm{T}$ & C I & C $\mathrm{F}$ & \\
\hline $\mathrm{T}$ & d F & $\mathrm{d}$ & d $\mathrm{T}$ & \\
\hline $\mathrm{T}$ & e $\mathrm{T}$ & $\mathrm{e}$ & e $\mathrm{F}$ & \\
\hline
\end{tabular}

